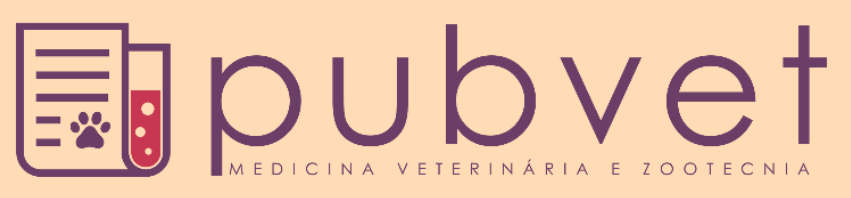

https://doi.org/10.31533/pubvet.v15n05a822.1-7

\title{
Cistorrafia em cão pós trauma automobilístico: Relato de caso
}

\author{
Antonio Jackson Sousa Lima ${ }^{1 *} \bullet$, Ivanilce Nunes Rodrigues ${ }^{1} \bullet$, Wagner Costa Lima ${ }^{2}$, \\ Dayanne Anunciação Silva Dantas Lima ${ }^{3} \theta$, Larissa Fernanda Soares Lima ${ }^{4} \theta$, Sérgio Henrique \\ Costa Júnior $^{4}$ (D), Vanessa Rodrigues Barbosa ${ }^{5}$, Yuri Luiz Boechat ${ }^{50}$
}

${ }^{I}$ Aprimorandos em Clínica Cirúrgica de cães e gatos, Universidade Federal do Piauí, Teresina - PI, Brasil

${ }^{2}$ Doutor, Docente do Curso de Medicina Veterinária, Universidade Federal do Piauí, Bom Jesus - PI, Brasil

${ }^{3}$ Doutora, Médica Veterinária em Hospital Veterinário Universitário, Universidade Federal do Piauí, Bom Jesus - PI, Brasil

${ }^{4}$ Mestrandos em Ciência Animal, Universidade Estadual do Maranhão, São Luís - MA, Brasil

${ }^{5}$ Acadêmicos em Medicina Veterinária, Universidade Federal do Piauí, Bom Jesus - PI, Brasil

*Autor para correspondência, E-mail: jacksonufpi@hotmail.com

Resumo. O sistema urinário de cães e gatos podem ser acometidos por diversas patologias, das quais umas das mais frequentes está a ruptura da vesícula urinária. Pode ser ocasionada por diversos fatores, destaca-se os traumáticos como mais comuns, como consequência do extravasamento da urina para a cavidade. Diversos sinais clínicos são observados, sendo que quando não tratados, assim como a causa primária, podem levar o paciente a óbito. $\mathrm{O}$ diagnóstico para tal enfermidade vai desde os exames físicos aos complementares e tem como tratamento definitivo a cistorrafia. $O$ presente trabalho relata um caso de uma ruptura de bexiga em cão ocasionada por um trauma automobilístico. O paciente em questão, após o acidente, foi atendido em clínica particular, onde foi diagnosticado com tal enfermidade mediante exames físicos. Em seguida foi encaminhado para o hospital veterinário universitário da Universidade Federal do Piauí para que fosse submetido ao procedimento cirúrgico de cistorrafia. Todos os procedimentos adotados, bem como a experiência do cirurgião foram de grande importância para a recuperação do paciente, que hoje se encontra totalmente recuperado.

Palavras chaves: Bexiga, cão, ruptura, procedimento cirúrgico

\section{Cistorraphy in a dog after car trauma: Case report}

\begin{abstract}
The urinary system of dogs and cats can be affected by several pathologies, of which one of the most frequent is the rupture of the urinary vesicle, which can be caused by several factors, which highlights the traumatic ones as more frequent, as a result of the extravasation from the urine to the cavity. Several clinical signs are observed, and when untreated, as well as the primary cause, they can lead the patient to death. The diagnosis for this disease ranges from physical exams to complementary exams and has cistorraphy as the definitive treatment. The present work reports a case of a bladder rupture in a dog caused by automobile trauma, the patient in question after the accident, was seen at a private clinic, where he was diagnosed with such a disease through physical examinations, then he was referred to the hospital university veterinarian at the Federal University of Piauí to undergo the cistorraphy surgical procedure, all procedures adopted as well as the surgeon's experience were of great importance for the recovery of the patient, who is now fully recovered.
\end{abstract}

Key words: Bladder, dog, rupture, surgical procedure 


\section{Cistorrafia en un perro después de un trauma automovilístico: Reporte de caso}

Resumen. El sistema urinario de perros y gatos puede verse afectado por diversas patologías, de las cuales una de las más frecuentes es la rotura de la vesícula urinaria, pudiendo ser provocada por varios factores, destacándose los factores traumáticos como más habituales y teniendo como consecuencia el escape de orina hacia la cavidad. Se observan varios signos clínicos, y cuando no se tratan, así como la causa primaria, pueden llevar al paciente a la muerte. El diagnóstico de esta enfermedad abarca desde exámenes físicos hasta exámenes complementarios y tiene la cistorrafia como tratamiento definitivo. El presente trabajo reporta un caso de ruptura de vejiga en un perro causado por traumatismo automovilístico, el paciente en cuestión luego del accidente fue atendido en una clínica privada, donde se le diagnosticó tal enfermedad mediante exámenes físicos, luego remitido al hospital. veterinario universitario de la universidad federal de Piauí para someterse al procedimiento quirúrgico de cistorrafia, todos los procedimientos adoptados, así como la experiencia del cirujano fueron de gran importancia para la recuperación del paciente, que ahora se encuentra totalmente recuperado.

Palabras clave: Vejiga, perro, rotura, procedimiento quirúrgico

\section{Introdução}

Diversas patologias podem acometer o sistema urinário de cães. Uma das mais frequentes é a ruptura de bexiga, que pode ser causada por atropelamentos, quedas, golpes abdominais violentos, objetos perfuro cortantes, fratura dos ossos da pelve, passagem de sonda uretral, por necrose, complicações durante uma cirurgia vesical ou por obstrução uretral prolongada ocasionada por cálculos ou por um tumor que obstrui a uretra proximal ou o trígono (Fossum, 2014; Nelson \& Couto, 2015).

Podem ser observados diversos sinais clínicos em decorrência do extravasamento de urina como: aumento de volume abdominal, dor, uremia, desidratação e hipovolemia, podendo ocorrer o óbito do paciente, caso o distúrbio não seja diagnosticado ou tratado (Fossum, 2014; Nelson \& Couto, 2015). Por isso a necessidade de um exame físico bem feito, principalmente nos casos de trauma, onde outras lesões associadas podem camuflar o quadro de ruptura da bexiga muitos animais apresentam lesão ortopédica concomitante, especialmente fraturas pélvicas (Slatter, 2007). Por isto, recomenda-se que em todos estes casos deve-se proceder à palpação e cateterização da bexiga.

O diagnóstico vai desde a observação do paciente, exames físicos, exames clínicos, ultrassonográficos e radiográficos, onde, que se utilizam de contraste para o estabelecimento do local e da extensão das lesões. É possível a visualização do extravasamento caso exista pequena laceração na parede vesical, e se o material de contraste é injetado enquanto estão sendo tomadas as radiografias (Slatter, 2007). O meio de contraste fica livre no interior da cavidade abdominal passando a delinear outros órgãos.

O tratamento definitivo para esses casos é cirúrgico, onde a ressecção da mesma pode ser necessária se o tecido estiver severamente danificado (Culp \& Silverstein, 2009). No entanto, antes do procedimento cirúrgico deve-se estabilizar o máximo possível o quadro da volemia sanguínea. $\mathrm{O}$ objetivo deste trabalho é relatar um caso clínico-cirúrgico de uma ruptura de bexiga em um cão SRD vítima de atropelamento.

\section{Relato de caso}

Um macho, da espécie canina, do sexo masculino, sem padrão de raça definida (SPRD), com dois anos e nove meses de idade, pesando cerca $4.700 \mathrm{~kg}$, foi atendido em uma clínica particular no $30 \mathrm{de}$ outubro, vítima de atropelamento que ocorreu no dia 26 de outubro. Durante o atendimento na data em questão, na anamnese o tutor relatou que o animal não estava se alimentando corretamente depois do ocorrido e que a ingestão de água tinha aumentado, estava urinando normalmente, mas estava defecando em pouca quantidade, durante o exame físico observou-se abdômen distendido, e sensibilidade dolorosa na palpação na região do abdômen. 
Na clínica particular foi realizado uma abdominocentese no qual foi constatado urina na cavidade abdominal, mediante isso o paciente foi diagnosticado com ruptura de bexiga, e foi feita medicação ambulatorial: Tramadol ( $2 \mathrm{mg} / \mathrm{kg}$ ) enrofloxacino $(5 \mathrm{mg} / \mathrm{kg})$ e cetoprofeno $(2 \mathrm{mg} / \mathrm{kg})$ sendo que todos foram aplicados por via intramuscular (IM). Na sequência, o paciente foi encaminhado para o Hospital Veterinário Universitário (HVU) do Campus Professora Cinobelina Elvas (CPCE) da Universidade Federal do Piauí (UFPI) no dia 30 de outubro, para que fosse realizado procedimento cirúrgico. Já no HVU o paciente foi novamente clinicado, onde se percebeu que ele apresentava reflexo de dor e hematomas por toda a região abdominal e prepúcio (lado direito mais acometido), com presença de escoriações nas mesmas regiões. No HVU, durante o exame físico o paciente apresentou frequência cardíaca de $128 \mathrm{bat} / \mathrm{min}$, temperatura retal de $36.8^{\circ} \mathrm{c}$ e frequência respiratória de $80 \mathrm{mov} / \mathrm{min}$. Foi feito novo tratamento ambulatorial, administrando ranitidina $(1 \mathrm{mg} / \mathrm{kg})$ e moropitant $(1 \mathrm{mg} / \mathrm{kg})$ por via subcutânea, em seguida foi solicitado exames complementares para fechar o diagnóstico, hemograma (eritrograma, plaquetograma e leucograma.) Além do exame ultrassonográfico da região (Figura 1), onde observou-se grande quantidade de líquido livre no abdômen (Figura 1A), mesentério apresentando ecogenidade elevada (Figura 1B), fígado ultrapassando os limites do gradil costal e a bexiga apresentou parede irregular com área de descontinuidade em região cranial (Figura 1C). Com os resultados dos exames o paciente foi encaminhado para cirurgia de emergência para realização de cistorrafia.

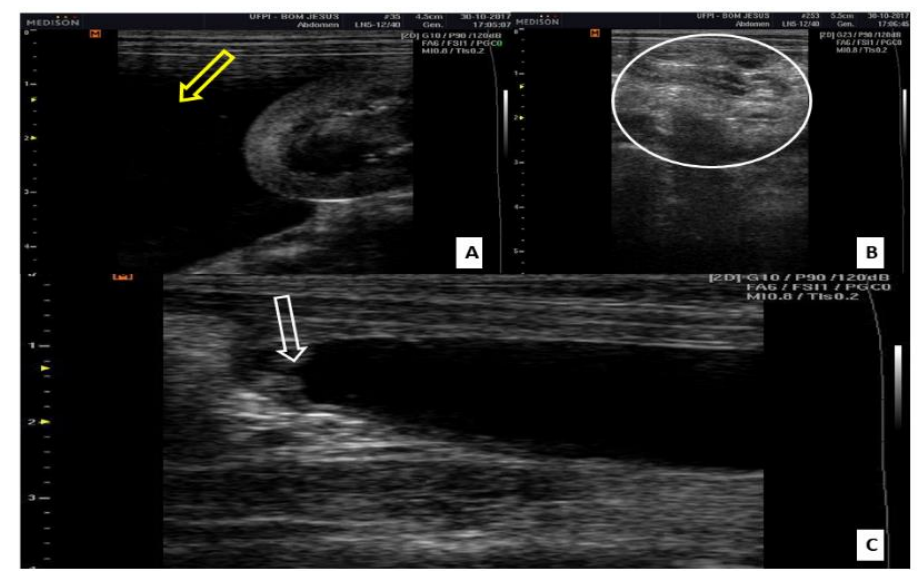

Figura 1. Canino, macho, SPRD, 2 anos e 9 meses, peso $4.7 \mathrm{~kg}$ com diagnostico de ruptura de bexiga após atropelamento. Ultrassonografia da região abdominal. A - Mostrando o rim e líquido na cavidade abdominal (seta amarela); B elevada ecogenidade do mesentério (círculo branco); C - Área irregular e descontinuidade da parede da bexiga na região cranial (seta branca).

Mediante autorização do tutor através do termo de autorização para o ato cirúrgico/anestésico, o paciente foi encaminhado para a sala de preparo, para a realização da tricotomia na região abdominal (Figura 2A) e aplicação da medicação pré-anestésica (midazolam $2 \mathrm{mg} / \mathrm{kg}$ e acepram $0.2 \mathrm{mg} / \mathrm{kg}$ ) via intramuscular, em seguida o paciente foi levado para o centro cirúrgico, onde o mesmo foi induzido a anestesia com propofol $(4 \mathrm{mg} / \mathrm{kg} /)$ via intravenosa, sendo feita a manutenção com a mesma dose, o paciente também recebeu anestesia epidural, no qual foi utilizado lidocaína $(0.2 \mathrm{mg} / \mathrm{kg}), \log$ o em seguida, ele foi entubado para receber oxigenação adequada (Figura 2B). Com o paciente já anestesiado e em decúbito dorsal, deu-se início ao procedimento, começando pela antissepsia, que foi feita com clorexidina alcoólica e gases esterilizadas, o movimento de escarificação adotado, foi o de espinha de peixe (Figura 2C). Prosseguiu-se com a colocação dos panos de campo, que são presos a pele do paciente com as pinças Backhaus (Figura 2D) e sob autorização do anestesista, foi dado início ao procedimento cirúrgico.

A técnica cirúrgica empregada foi iniciada com uma incisão retroumbilical sobre a linha média ventral, de aproximadamente $6 \mathrm{~cm}$ (Figura 3A). Ao acessar a cavidade abdominal, visualizou-se grande quantidade de líquido, uma compressa cirúrgica foi utilizada para drenar parte do líquido ali presente para facilitar a manipulação da cavidade e ainda evitar maior contaminação no campo cirúrgico (Figura 


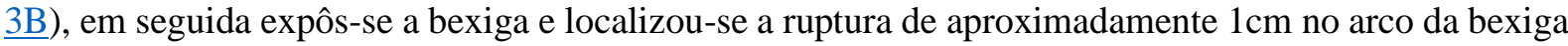
(Figura 3C). As bordas da mesma estavam desvitalizadas, foi feita então uma revitalização do tecido com uma tesoura (Figura 3D). A Sutura da parede da bexiga foi realizada em dois planos, tanto a primeira quanto a segunda foram realizadas no padrão de Cushing simples continuo utilizando fio absorvível de poligalactina 910 (vicril) (Figura 4A). Logo após a sutura, foi passada uma sonda uretral (Figura 4B), onde com o auxílio de uma seringa foi ejetada solução de cloreto de sódio $0,9 \%$, até encher a mesma, esse procedimento teve por finalidade realizar a lavagem da bexiga e verificar se a mesma apresentava extravasamento de líquido (Figura 4C), seguiu se retirando o conteúdo injetado, o mesmo apresentava aspecto sanguinolento, repetiu-se esse procedimento seguidas vezes até que o líquido retirado estivesse com aspecto transparente. Quanto a sutura, a mesma não apresentou extravasamento de líquidos.

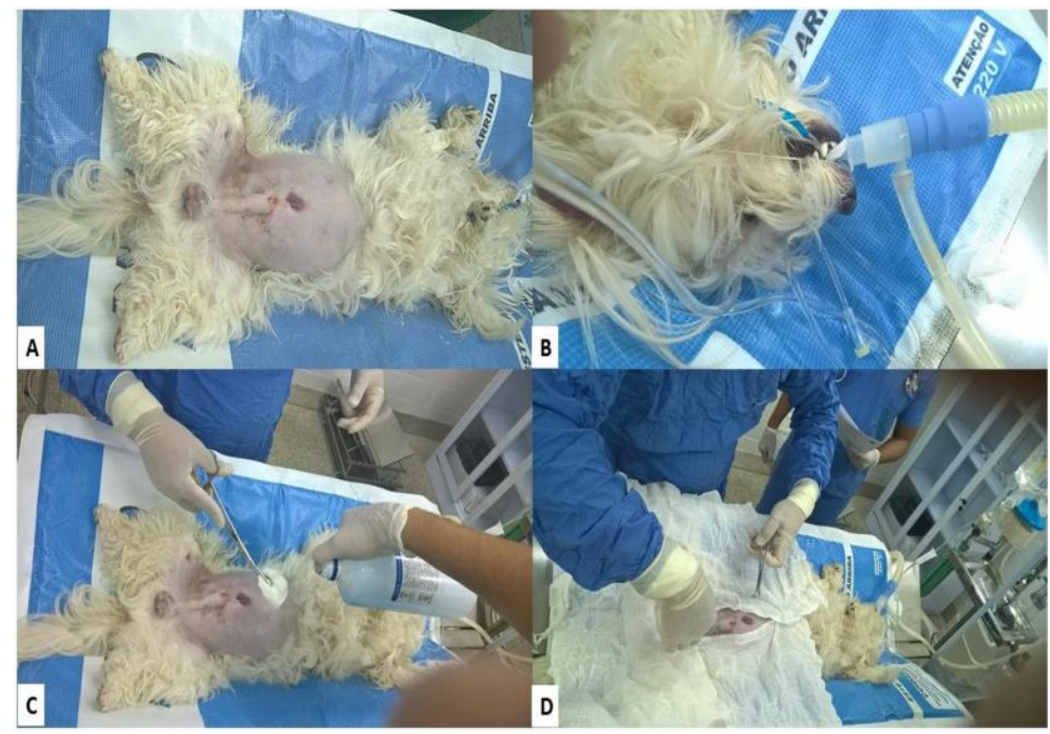

Figura 2. Canino, macho, SPRD, 2 anos e 9 meses, peso $4.7 \mathrm{~kg}$ com diagnostico de ruptura de bexiga após atropelamento. Procedimentos pré-operatórios. A - Tricotomia da região abdominal; B - Intubação orotraqueal; $\mathbf{C}$ - antissepsia da região abdominal; D - colocação dos panos de campo.

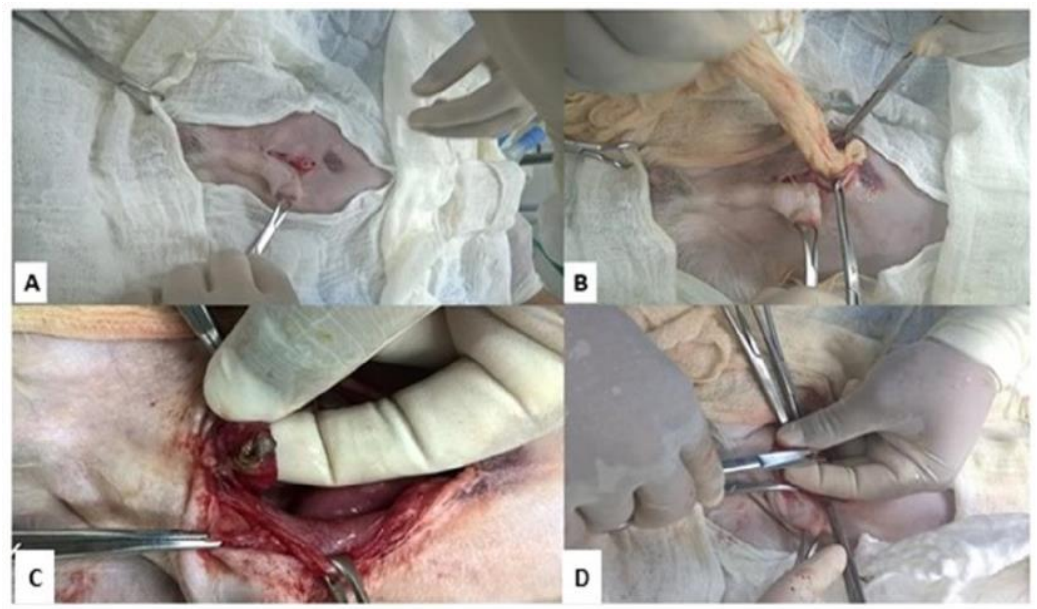

Figura 3. Canino, macho, SPRD, 2 anos e 9 meses, peso $4.7 \mathrm{~kg}$ com diagnostico de ruptura de bexiga após atropelamento. Procedimentos peri-operatórios. A - Incisão retroumbilical; B - Drenagem do líquido da cavidade abdominal com utilização de compressa cirúrgica; C - Ruptura da bexiga; D - Revitalização do tecido.

Prosseguiu-se fazendo a lavagem da cavidade para a retirada de líquidos que ali ainda continha, onde foi utilizada solução de cloreto de sódio $0,9 \%$ para lavar e um aspirador cirúrgico para sugar o líquido (Figura 5A e B), após a cavidade ter sido lavada deu-se início ao fechamento da cavidade, onde a camada muscular foi suturada com fio de nylon 3.0, e pontos em U (Figura 5C), suturou-se o subcutâneo com 
fio catgut 3.0 para reduzir espaço morto com o padrão de sutura continuo simples e a pele foi suturada com fio de nylon $3.0 \mathrm{em}$ pontos em U. O paciente foi deixado sondado uretralmente para evitar que ocorra deiscência da sutura na bexiga, quando a mesma se expandisse com o acúmulo da urina (Figura 5D).

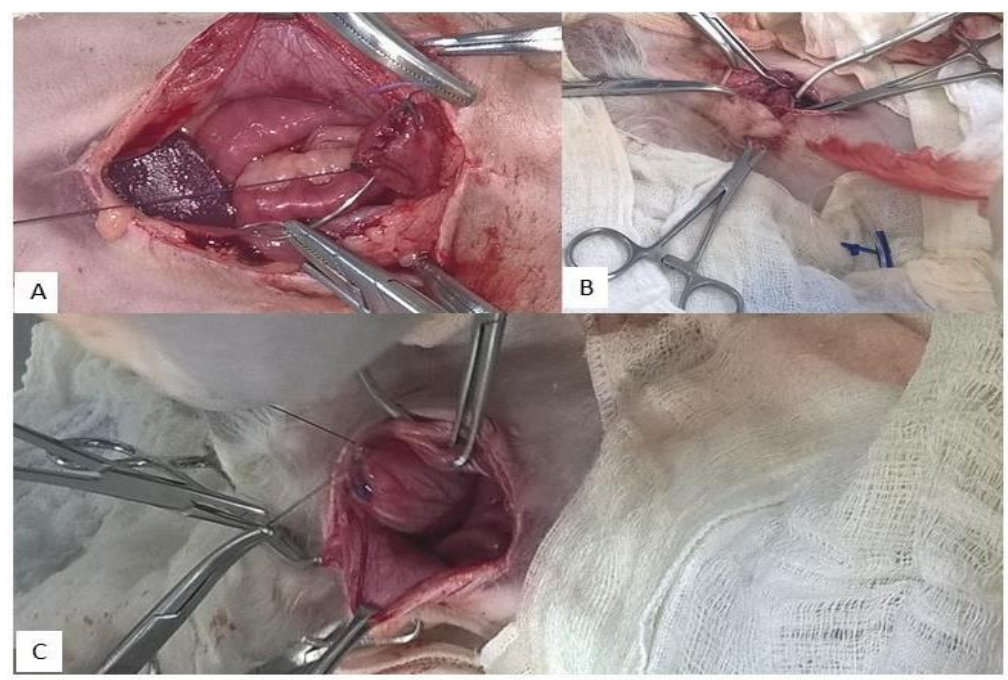

Figura 4. Canino, macho, SPRD, 2 anos e 9 meses, peso $4.7 \mathrm{~kg}$ com diagnostico de ruptura de bexiga após atropelamento. Procedimentos peri-operatórios. A - Cistorrafia; B Passagem de sonda uretral; $\mathbf{C}$ - Infusão de solução de $\mathrm{NaCl}$ para verificar se há extravasamento.

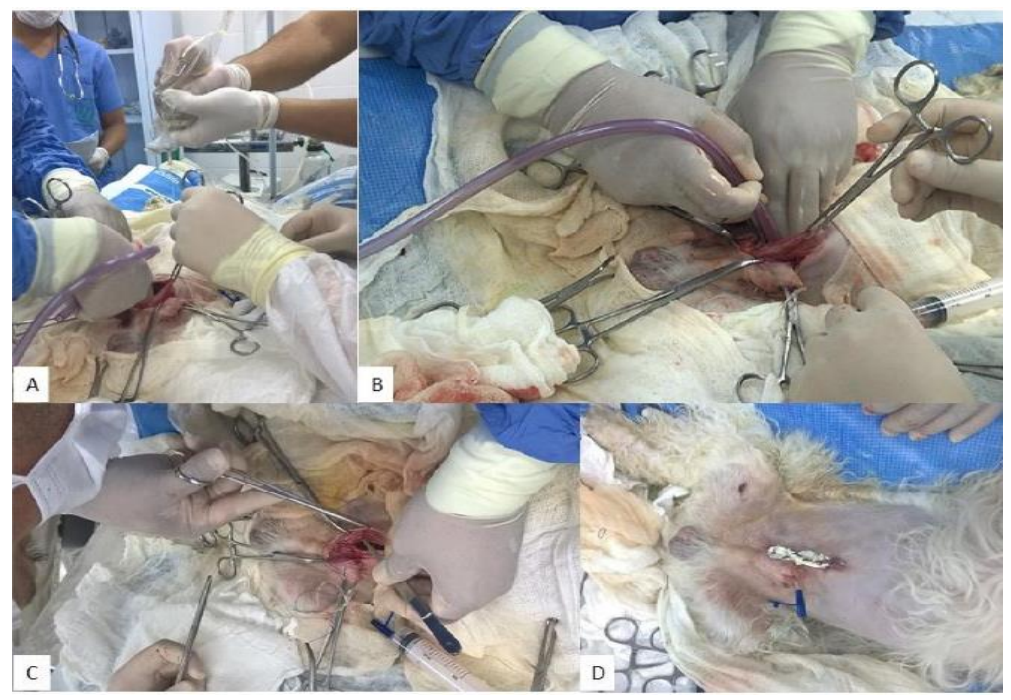

Figura 5. Canino, macho, SPRD, 2 anos e 9 meses, peso $4.7 \mathrm{~kg}$ com diagnostico de ruptura de bexiga após atropelamento. Procedimentos Peri e pós-operatórios. A - Lavagem da cavidade; B - Drenagem do líquido da cavidade abdominal usando aspirador cirúrgico; C - Miorrafia abdominal; D - Finalização do procedimento cirúrgico com fixação de sonda uretral.

Para o pós-operatório foi prescrito enrofloxacina $5 \mathrm{mg} / \mathrm{kg}$ de 12/12 horas, meloxicam 0,5 mg a cada $24 / 24$ horas, todos por via oral, e pomada cicatrizante para uso tópico, passar sobre a ferida depois de limpa, 3 vezes ao dia, e ainda se recomendou o uso de colar elisabetano 24 horas por dia até a retirada dos pontos.

\section{Discussão}

A ruptura da vesícula urinária pode se dar de forma traumática ou espontânea (Busnaro \& Porfirio, 2004; Ettinger et al., 2017). A lesão traumática pode ser causada por atropelamentos, quedas, golpes abdominais violentos, objetos perfuro-cortantes, ou fratura dos ossos da pelve (Busnaro \& Porfirio, 2004; Slatter, 2007). Além destas perfurações traumáticas, a vesícula urinária pode eventualmente ser 
rompida de forma iatrogênica, durante a passagem de sonda uretral (Ettinger et al., 2017). A ruptura espontânea ocorre normalmente em quadros de obstrução uretral prolongado ou necrose da parede, durante uma torção ou retroflexão vesical. No caso em questão o paciente foi vítima de atropelamento no qual ocasionou a ruptura de bexiga. Sakamoto et al. (2008) afirmam que normalmente este tipo de lesão é decorrente de fraturas pélvicas, porém, o paciente não apresentava fraturas.

Qualquer animal apresentado após traumatismo causado por veículo deve ser avaliado para possível trauma de trato urinário (Fossum, 2014) principalmente machos, visto que os mesmos sempre retém urina na bexiga, para a marcação de territórios. Muitas vezes os animais que sofrem esse tipo de acidente do trato urinário se apresentarão com hematúria antes que os sinais de um uroperitônio sejam aparentes (Culp \& Silverstein, 2009). Na clínica particular o diagnóstico foi dado perante a anamnese, os sinais clínicos que o paciente apresentava e pelo resultado da abdominocentese, que constatou urina na cavidade, já no HVU o diagnóstico foi fechado tanto pelas informações repassadas pela clínica, pelos sinais clínicos como também pela ultrassonografia. De acordo com Fossum (2014) o diagnóstico de ruptura vesical baseia-se primeiramente no exame ultrassonográfico, onde se deve introduzir uma sonda uretral no paciente e injetar solução fisiológica por esta sonda, observando a distensão da bexiga e o acúmulo ou não de líquido na cavidade abdominal. Esse paciente apresentava líquido na cavidade, não foi preciso injetar solução fisiológica, a bexiga do mesmo ainda continha urina.

Segundo Slatter (2007) os sinais de traumatismos no trato urinário podem ser vagos. Hematúria, disúria, dores abdominais, a ausência da bexiga palpável, acúmulo de líquidos no interior do abdômen e contusões abdominais e perineais, são os sinais mais iniciais, posteriormente pode apresentar depressão progressiva, episódios de vomito, e alterações metabólicas associadas a uremia em evolução. No caso em questão, o paciente estava urinando normalmente, mas os sinais clínicos apresentados durante a consulta como: acúmulo de líquido na cavidade e dores abdominais, levaram a se suspeitar de ruptura de bexiga, o que foi previamente confirmada após a abdominocentese, que se constatou urina na cavidade.

O diagnóstico pode ser confirmado de várias formas. Dentre os quais pode-se introduzir um cateter e verificar se existe a presença de urina, se este exame demonstrar a ausência de urina, pode-se proceder à injeção de solução fisiológica por uma sonda com uma seringa, succionando logo em seguida, observando se o líquido retornará. Caso se observe acúmulo de líquido na cavidade abdominal pode se fazer uma abdominocentese. Apesar destes exames se mostrarem eficientes, o método mais indicado para se observar ruptura no sistema urinário é através de uma radiografia contrastada, onde através de uma sonda uretral é aplicado um corante inerte, que irá se difundir por toda a extensão da bexiga e da uretra, onde será possível diagnosticar a ruptura através da visualização do contraste depositado no interior da cavidade abdominal e da ausência do contorno normal da bexiga, porém este exame não pode ser realizado devido a indisponibilidade do aparelho de radiografia. Nesse caso o diagnóstico foi fechado previamente após ser realizado uma abdominocentese e confirmando urina na cavidade, e em seguida através da ultrassonografia que mostrou irregularidades na parede da bexiga. A abdominocentese deve ser feita com auxílio por meio de ultrassom, para minimizar os riscos de perfurações de órgãos e facilitar a coleta ou retirada de líquido, deve ser feita assepticamente para prevenir a inoculação de bactérias e que ocorra uma peritonite séptica, no caso em questão não se utilizou aparelho de ultrassom, sendo feita apenas com a experiência do clínico e limpeza profunda do local.

O paciente recebeu fluidoterapia intravenosa afim de estabilizar o quadro que o mesmo apresentava, condizendo com Silverstein \& Hopper (2014) que afirmam que a administração de fluidoterapia durante o período pré e pós-cirúrgico visa reduzir os níveis de ureia e creatinina no sangue e avaliar a perfusão renal do paciente. Pequenas lacerações da bexiga ou da uretra podem dispensar cirurgia. Um cateter urinário e um sistema de drenagem fechado podem ser deixados no lugar por 3 a 10 dias (Macintire et al., 2007). Contudo, pelo grau da ruptura apresentada pelo paciente a correção cirúrgica era a única alternativa para a cura do mesmo. O reparo cirúrgico é o tratamento definitivo para a maioria das lacerações da bexiga. Ressecção da mesma pode ser necessária se o tecido aparece severamente danificado (Culp \& Silverstein, 2009). Foi feita uma incisão abdominal da região do umbigo até o púbis, para o acesso à bexiga mesma técnica relatada por Fossum (2014). Foi feita revitalização do tecido e duas camadas de sutura, o que condiz com Fossum (2014) que afirma, que é necessário que se retire o tecido desvitalizado ou necrosado e suture a abertura com uma ou duas camadas de sutura contínua. 
Não houve intercorrências durante o procedimento cirúrgico e nem no pós-operatório; porém, Fossum (2014) afirma que a maior complicação de cirurgia de bexiga é o vazamento urinário, especialmente se não for obtido um fechamento impermeável ou se os tecidos desvitalizados forem suturados e subsequentemente se abrirem. O que nos diz que a técnica de cistorrafia feita, foi de grande importância na recuperação do paciente. Ainda de acordo com Fossum (2014) o prognóstico é excelente para animais com ruptura traumática de bexiga.

\section{Conclusão}

A ruptura de bexiga é considerada uma emergência em pequenos animais, sendo que a detecção da mesma o mais rápido possível é de grande importância para a saúde do animal. No presente relato, conclui-se que a intervenção cirúrgica associada com a técnica utilizada, bem como a experiência do cirurgião, foi de grande importância para a recuperação do paciente.

\section{Referências}

Busnaro, C. A., \& Porfirio, L. C. (2004). Ruptura vesical em cão: Relato de caso. Arquivos de Ciências Veterinárias e Zoologia Da UNIPAR, 7(Supl. 2), 1-19.

Culp, W. T. N., \& Silverstein, D. C. (2009). Abdominal trauma. In D. Silverstein \& K. Hopper (Eds.), Small animal critical care medicine (pp. 667-670). Saunders: Elsevier.

Ettinger, S. J., Feldman, E. C., \& Cote, E. (2017). Textbook of Veterinary Internal Medicine-eBook. Elsevier Health Sciences.

Fossum, T. W. (2014). Cirurgia de pequenos animais (4th ed., Vol. 1). Elsevier Brasil.

Macintire, D. K., Drobatz, K. J., Haskins, S. C., \& Saxon, W. D. (2007). Emergência e cuidados intensivos em pequenos animais. Manole.

Nelson, R. W., \& Couto, C. G. (2015). Medicina interna de pequenos animais (Issue 1). Elsevier Editora.

Sakamoto, S. S., Ferreira, G. T. N. M., Silva, C. M., Abimussi, C. J. X., Eugênio, F. R., \& Andrade, A. L. (2008). Cistotomia como alternativa de tratamento em cão com ruptura uretral recidivante-relato de caso. Veterinária e Zootecnia, 2(Supl. 1), 1-34.

Silverstein, Deborah, \& Hopper, K. (2014). Small animal critical care medicine-E-Book. Elsevier Health Sciences.

Slatter, D. H. (2007). Manual de cirurgia de pequenos animais (Vol. 2). Manole São Paulo.

\section{Histórico do artigo:}

Recebido: 19 de dezembro de 2020 Aprovado: 19 de janeiro de 2021.

Disponível online: 29 de abril de 2021.
Licenciamento: Este artigo é publicado na modalidade Acesso Aberto sob a licença Creative Commons Atribuição 4.0 (CC-BY 4.0), a qual permite uso irrestrito, distribuição, reprodução em qualquer meio, desde que $o$ autor e a fonte sejam devidamente creditados. 